\title{
Correction to: Further phenotypic delineation of the auriculocondylar syndrome type 2 with literature review
}

\author{
Ewelina Bukowska-Olech ${ }^{1} \cdot$ Anna Sowińska-Seidler ${ }^{1} \cdot{\text { Filip } \text { Łojek }^{1} \cdot \text { Delfina Popiel }}^{2} \cdot$ Joanna Walczak-Sztulpa $^{1}$. \\ Aleksander Jamsheer ${ }^{1,2}$
}

Published online: 12 November 2020

(C) Institute of Plant Genetics, Polish Academy of Sciences, Poznan 2020

\section{Correction to: Journal of Applied Genetics (2020)}

https://doi.org/10.1007/s13353-020-00591-3

The original article contains an error. In the Introduction section, after MIM should be placed a colon as follows; ACS1 (MIM: 602483), ACS2 (MIM: 600810), and ACS3 (MIM: 131240). Under the "Next-generation and Sanger sequencing methods" heading, the chromosomal localization of the variant should be: chr20:9389727. Lastly, Fig. 2 was replaced with the file of better quality.

The original article has been corrected.

Publisher's note Springer Nature remains neutral with regard to jurisdictional claims in published maps and institutional affiliations.

The online version of the original article can be found at https://doi.org/ 10.1007/s13353-020-00591-3

Aleksander Jamsheer

jamsheer@wp.pl

1 Department of Medical Genetics, Poznan University of Medical, Sciences, Rokietnicka 8 Street, 60-806 Poznan, Poland

2 Centers for Medical Genetics GENESIS, Dąbrowskiego 77A Street, 60-529 Poznan, Poland 